\title{
Fatty Acid Composition, Isoflavone and L-3,4-dihydroxyphenylalanine (L-dopa) Contents in Different Parts of Faba Bean (Vicia faba) Genotypes
}

\author{
Jaihyunk Ryu ${ }^{1}$, Dong-Gun Kim ${ }^{1}$, Min-Kyu Lee ${ }^{1}$, Jung Min Kim ${ }^{1}$, Min Jeong Hong ${ }^{1}$, Kyung-Yun Kang ${ }^{2}$, \\ Seok Hyun Eom ${ }^{3}$, Si-Yong Kang ${ }^{1}$, Jin-Baek Kim', Soon-Jae Kwon ${ }^{1}$ * \\ ${ }^{1}$ Advanced Radiation Technology Institute, Korea Atomic Energy Research Institute, Jeongup 56212, Korea \\ ${ }^{2}$ Suncheon Research Center for Natural Medicines, Suncheon 57922, Korea \\ ${ }^{3}$ Department of Horticultural Biotechnology, College of Life Sciences, Kyung Hee University, Yongin 17104, Korea
}

\begin{abstract}
The faba bean, one of the few crops that produces L-3,4-dihydroxy-phenylalanine (L-dopa) naturally, is also a good source of fatty acids and isoflavones. This study analyzed fatty acids, L-dopa and isoflavones in the leaves, immature pods and seeds of selected high-yielding faba bean genotypes spring-sown in Korea. The most abundant fatty acids in the leaves, immature pods and seeds were linolenic acid (58.6-63.7\%), linoleic acid (46.9-58.9\%), and linoleic acid (45.7-63.6\%), respectively. The L-dopa content was highest in the leaf for all the faba bean genotypes except PI430715 and PI614810 where it was highest in the immature pods. The $\alpha$-linolenic acid and L-dopa contents of the seed and immature pod of the PI430715 and PI614810 genotypes were the highest of all the genotypes. Four isoflavones (daidzin, genistin, daidzein and genistein) were detected with levels of daidzin and genistin generally higher than those of daidzein and genistein in each part of the faba bean. The L-dopa content was correlated $(P \leq 0.05)$ with those of five fatty acids (oleic, gondoic, phytanic, $\alpha$-linolenic, and behenic acid). Overall, the PI430715 and PI614810 faba bean genotypes with their higher L-dopa and $\alpha$-linolenic acid contents were the most functional. This study may help identify optimal genotypes for breeding new cultivars which provide functional compounds to treat Parkinson's disease or use in foods.
\end{abstract}

Keywords Correlation analysis, GC-MS, Faba bean, UPLC

\section{INTRODUCTION}

The faba bean (Vicia faba L.) is one of the most common legume crops in many countries, traditionally used for animal feeding and as human food (Goyoaga et al. 2008). The faba bean is an erect, coarse, leafy annual herb whose pods may be greenish black, brown or black in color. Its seeds may be oblong, oval, flattened and rounded whose color can vary from white, reddish brown, greenish brown, and purple to black. The seeds vary greatly in size depending on the variety. Adsule and Akpapunam (1996) reported that the faba bean can be divided into three botanical varieties on the basis of their seed size: smaller seeds ( $V$. faba L. var. minor), medium seeds ( $V$. faba L. var. equina), and larger seeds ( $V$. $f a b a$ L. var. major). The faba bean is known by a variety of common names such as faba bean, field bean, broad bean, horse bean, tick bean, and Windsor bean. Faba beans form an important part of the diet for people in China, Egypt, Europe and Latin America (Adsule and Akpapunam 1996). The seeds are rich in protein and starch, and valued for use in human food and animal feed (Crepon et al. 2010). The immature pods of faba beans are soft in texture and can be added to stews and soups or used as a vegetable. The young leaves of the faba

Received October 31, 2017; Revised November 20, 2017; Accepted November 20, 2017; Published December 1, 2017

*Corresponding author Soon-Jae Kwon, soonjaekwon@kaeri.re.kr, Tel: +82-63-570-3312, Fax: +82-63-570-3814 
bean plant can also be used as a vegetable and as animal feed (Goyoaga et al. 2008; Crepon et al. 2010).

The faba bean is one of the best natural plant sources of L-3,4-dihydroxy-phenylalanine (L-dopa). L-dopa is the precursor of the neurotransmitter dopamine and its synthesis involves the use of tyrosinase to convert tyrosine to L-dopa, a useful drug for the treatment of Parkinson's disease (Fox and Brotchie 2014). In humans, L-dopa can cross the blood-brain barrier and be converted to dopamine in the brain. Chemically-synthesized L-dopa is the main ingredient of several prescription drugs used in therapy for dopamine replacement in patients with Parkinson's disease (Rabey et al. 1993; Hu et al. 2015). It is well known that the L-dopa content of the faba bean is generally affected by genetic and environmental factors such as cultivar type, harvest time, location and temperature (Goyoaga et al. 2008; Crepon et al. 2010, Hu et al. 2015). Although different parts of the faba bean are used, there have been no studies on the L-dopa content of faba beans grown in the environment conditions of Korea.

The widespread use of legume crops makes this food group an important and diverse source of fatty acids and isoflavones in human nutrition (Kirakosyan et al. 2004; Yoshida et al. 2009). Therefore, evaluating the fatty acid and isoflavone contents of legume crops is important and beneficial for the food and pharmaceutical industries (Hamberg and Fahistadius 1992; Kirakosyan et al. 2004;
Yoshida et al. 2009). Recently, breeders have developed new varieties of legume which are more productive and nutritious with improved levels of fatty acids and isoflavones. Although the fatty acid and isoflavone contents of the faba bean seeds, leaves and stems have been studied (Robert and Griffiths 1984; Hamberg and Fahistadius 1992; Kirakosyan et al. 2004; Yoshida et al. 2009), there have been no studies on the immature pod or the fatty acid and isoflavone contents of faba beans grown in Korea. The aim of the present study is therefore to investigate the L-dopa, isoflavone and fatty acid contents of the leaves, immature pods and seeds of selected faba bean varieties with a high yield, which are spring-sown in Korea.

\section{MATERIALS AND METHODS}

\section{Plant materials and harvesting}

Ten faba bean genotypes were obtained from the United States Department of Agriculture (USDA) in 2014 (Table 1). These genotypes were then cultivated from 2014 to 2015 at the breeding farm of the Advanced Radiation Technology Institute at the Korean Atomic Energy Research Institute (Jeong-eup, Republic of Korea). The faba beans were selected on the basis of high seed and biomass production after spring sowing in early March. To

Table 1. Origin, morphological characteristics, and yield traits of the faba bean genotypes used in this study.

\begin{tabular}{|c|c|c|c|c|c|c|c|c|c|c|}
\hline No. & $\begin{array}{c}\text { Accession } \\
\text { number }\end{array}$ & Origin & $\begin{array}{l}\text { Leaf } \\
\text { size }\end{array}$ & $\begin{array}{l}\text { Leaf } \\
\text { shape }\end{array}$ & $\begin{array}{l}\text { Pod } \\
\text { size }\end{array}$ & $\begin{array}{l}\text { Seed } \\
\text { size }\end{array}$ & $\begin{array}{l}\text { Seed } \\
\text { color }\end{array}$ & $\begin{array}{c}\text { Flowering } \\
\text { time }\end{array}$ & $\begin{array}{c}\text { No. of } \\
\text { Seed } \\
\text { (ea/plant) }\end{array}$ & $\begin{array}{c}\text { One hundred } \\
\text { seed weight } \\
(100 \text { ea/g) }\end{array}$ \\
\hline 1 & PI252004 & Turkey & Small & Spatulate & Small & Medium & Purple & 29. Apr & $141.0 \mathrm{c}^{\mathrm{z})}$ & $98.9 \mathrm{~b}$ \\
\hline 2 & PI284345 & Italy & Meddle & Elliptic & Small & Medium & Brown & 6. May & $75.4 f$ & $97.8 b$ \\
\hline 3 & PI366039 & Argentina & Meddle & Elliptic & Small & Medium & Black & 13. May & $123.3 \mathrm{~d}$ & $93.3 b$ \\
\hline 4 & PI369511 & Turkey & Meddle & Elliptic & Small & Medium & Brown & 29. Apr & $88.5 \mathrm{e}$ & $85.4 b$ \\
\hline 5 & PI430715 & Hungary & Large & Spatulate & Small & Medium & Brown & 6. May & $155.0 \mathrm{~b}$ & $86.4 \mathrm{~b}$ \\
\hline 6 & PI469147 & Iran & Large & Ovate & Meddle & Medium & Brown & 6. May & $122.0 \mathrm{~d}$ & $87.9 c$ \\
\hline 7 & PI533728 & Spain & Meddle & Ovate & Large & Medium & Brown & 13. May & $145.7 \mathrm{bc}$ & $87.8 \mathrm{~d}$ \\
\hline 8 & PI567883 & Turkey & Meddle & Spatulate & Large & Large & Yellow & 13. May & $87.0 \mathrm{e}$ & $122.2 \mathrm{a}$ \\
\hline 9 & PI614810 & USA & Meddle & Ovate & Small & Small & Brown & 13. May & $160.5 \mathrm{a}$ & $38.6 \mathrm{e}$ \\
\hline 10 & PI655319 & Morocco & Meddle & Spatulate & Large & Large & Yellow & 6. May & $65.8 \mathrm{~g}$ & $135.7 \mathrm{a}$ \\
\hline
\end{tabular}

${ }^{\mathrm{z})}$ The letters above each point indicate a significant difference at the 0.05 probability level (Duncan's multiple range tests, $\mathrm{n}=3)$. 
select the superior genotypes, we evaluated their morphological and growth characteristics and their leaf size, pod size, seed size, seed color, flowering time, seed yield, and the 100-seed weight. We classified the genotypes into three botanical varieties on the basis of their seed size and 100-seed weight (Agung and McDonald 1998); the latter as under $80 \mathrm{~g}$ ( $V$. faba L. var. minor), 80-120 $\mathrm{g}(\mathrm{V}$. $f a b a \mathrm{~L}$. var. equina), and over $120 \mathrm{~g}$ ( $V$. faba L. var. major). Faba beans collected from three biological replicates were used for each sample. The leaves, immature pods, and seeds of the faba bean plants were harvested (Fig. 1) and then freeze dried for later analysis. The representative weather conditions at the breeding farm during the faba bean cultivation are shown in Table 2 .

\section{Fatty acids analysis}

For GC-MS analysis, the fatty acids were extracted as described by Ryu et al. (2017), with the following modifications. The powdered freeze-dried material $(100 \mathrm{~g})$ of the leaf, immature pod, or seed was extracted in $100 \mathrm{~mL}$ $n$-hexane for 4 hours, then $1 \mathrm{~mL} 2 \mathrm{~N}$ potassium hydroxide in methanol was added. After the sample centrifugation for 5 minutes at $3000 \times \mathrm{g}$, the collected supernatant was filtered using a $0.45-\mu \mathrm{m}$ syringe filter. The fatty acid composition of the different parts of the faba bean plant was analyzed using a GC-MS (Plus-2010, Shimadzu, Japan) instrument

\section{A}

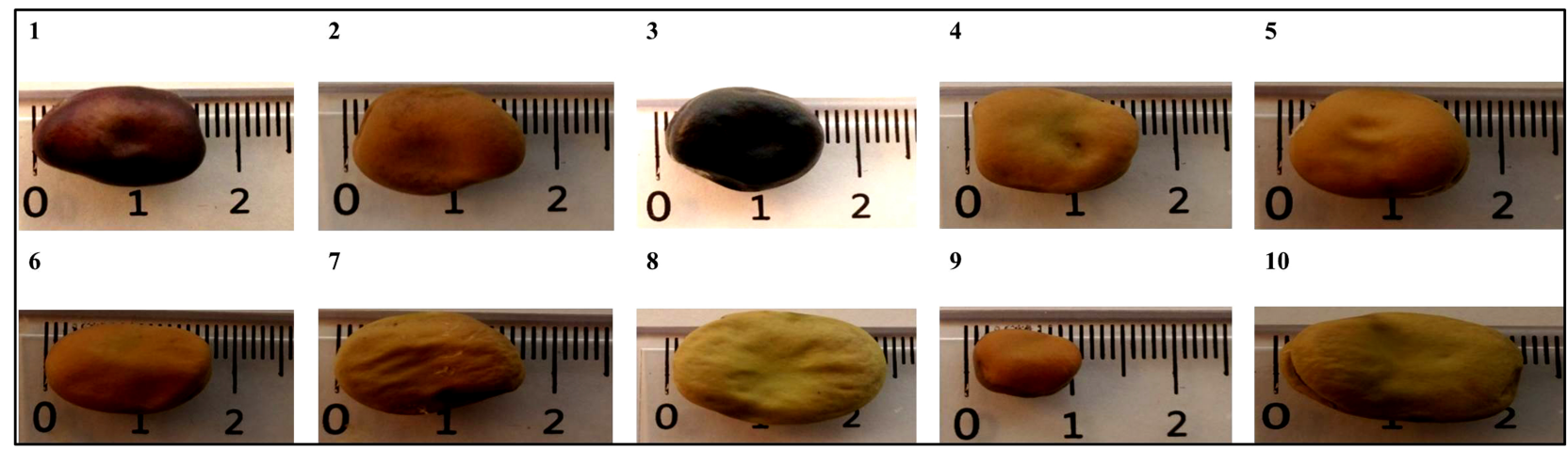

B

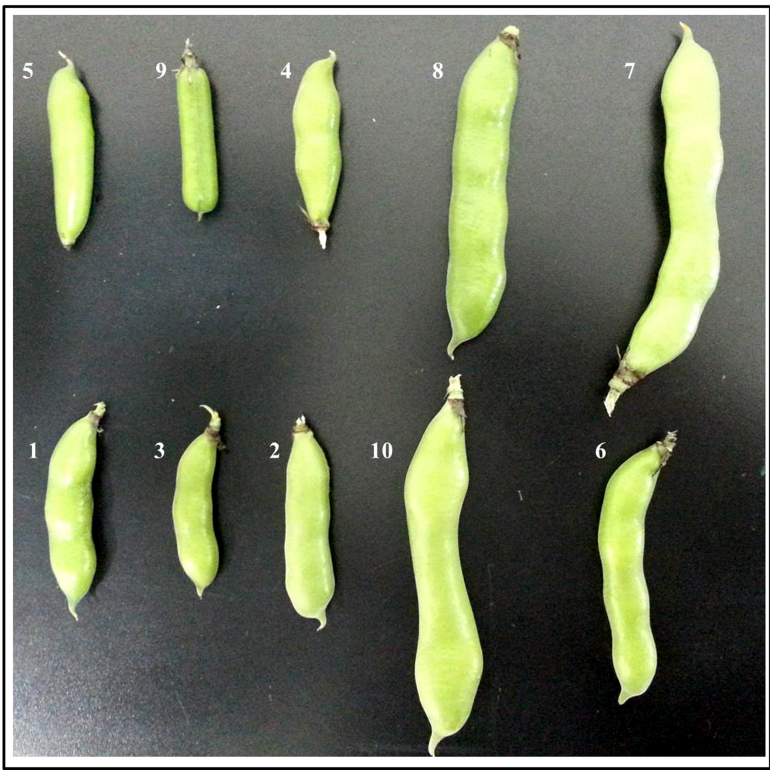

C

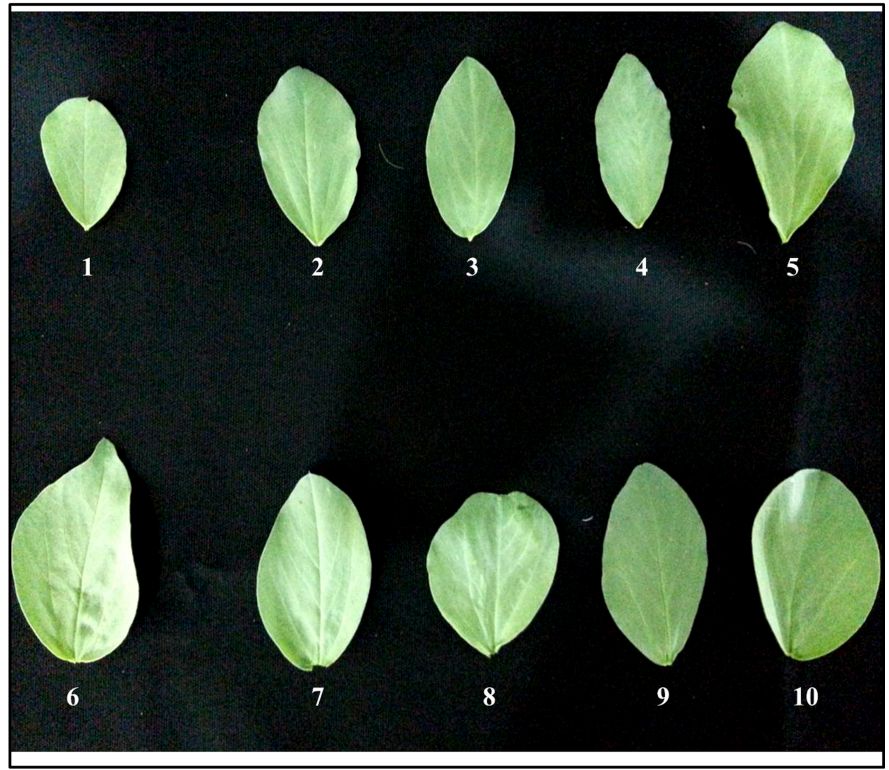

Fig. 1. Morphological profiles of different parts of the faba bean genotypes. (A) seed, (B) immature pod, (C) leaf, 1-10: accession numbers listed in Table 1. 
Table 2. The weather conditions of cultivation area.

\begin{tabular}{|c|c|c|c|c|c|c|c|c|c|c|}
\hline & \multicolumn{3}{|c|}{$\begin{array}{c}\text { Temperature } \\
\left({ }^{\circ} \mathrm{C}\right)\end{array}$} & \multicolumn{3}{|c|}{$\begin{array}{c}\text { Humidity } \\
(\%)\end{array}$} & \multicolumn{2}{|c|}{$\begin{array}{l}\text { Wind speed } \\
(\mathrm{m} / \mathrm{s})\end{array}$} & \multirow{2}{*}{$\begin{array}{c}\text { Solar radiation } \\
\left(\mathrm{w} / \mathrm{m}^{2}\right)\end{array}$} & \multirow{2}{*}{$\begin{array}{c}\begin{array}{c}\text { Rainfall } \\
(\mathrm{mm})\end{array} \\
\text { Total } \\
\end{array}$} \\
\hline & Mean & Min. & Max. & Mean & Min. & Max. & Mean & Max. & & \\
\hline March & 8.26 & -3.6 & 25.9 & 72.71 & 13 & 113 & 0.87 & 10 & 177.45 & 38.0 \\
\hline Apr. & 15.64 & 5.2 & 29.2 & 87.57 & 15 & 113 & 0.77 & 9 & 240.59 & 122.5 \\
\hline May & 20.80 & 7.4 & 35.1 & 72.77 & 16 & 113 & 0.81 & 10 & 281.15 & 43.0 \\
\hline Jun. & 24.62 & 14.3 & 34.8 & 89.07 & 22 & 113 & 0.57 & 13 & 261.03 & 68.5 \\
\hline
\end{tabular}

equipped with an HP-88 capillary column (J\&W Scientific, $60 \mathrm{~m} \times 0.25 \mathrm{~mm} \times 0.25 \mathrm{~m})$ under the following conditions: ionization voltage, $70 \mathrm{eV}$; mass scan range, 50-450 mass units; injector temperature, $230^{\circ} \mathrm{C}$; detector temperature, $230^{\circ} \mathrm{C}$; injection volume, $1 \mu \mathrm{L}$; split ratio, $1: 30$; carrier gas, helium; and flow rate, $1.7 \mathrm{~mL} /$ minute. The column temperature program specified an isothermal temperature of $40^{\circ} \mathrm{C}$ for 5 minutes increasing to $180^{\circ} \mathrm{C}$ at a rate of $5^{\circ} \mathrm{C} /$ minute then a subsequent increase to $28^{\circ} \mathrm{C}$ at a rate of $1^{\circ} \mathrm{C} /$ minute. We identified the substances present in the extracts according to their retention time (RT) and using the mass spectra database (NIST 62 Library).

\section{L-dopa and isoflavones analyses}

The L-dopa and isoflavone compounds were analyzed using a UPLC system (CBM-20A, Shimadzu Co., Kyoto, Japan) with two gradient pump systems (LC-30AD, Shimadzu), an UV detector (SPD-M30A, Shimadzu), an auto sample injector (SIL-30AC, Shimadzu), and a column oven (CTO-30A, Shimadzu).

L-dopa was extracted from each sample as described by Takashi et al. (2011), with some modifications. Briefly, $0.5 \mathrm{~g}$ of the freeze-dried sample were treated with $5 \mathrm{~mL}$ acetonitrile : water : formic acid $(80: 20: 1, \mathrm{v} / \mathrm{v})$ for 24 hours, with periodic vortexing. The material was filtered through a $0.45-\mu \mathrm{m}$ membrane filter. Three replicates of the extract were analyzed from each sample. Separation was achieved on an XR-ODS column $(3.0 \times 100 \mathrm{~mm}, 1.8 \mu \mathrm{m}$, Shimadzu) using a linear gradient elution program with a mobile phase containing solvent A (water with $0.1 \%$ trifluoroacetic acid) and solvent B (acetonitrile with $0.1 \%$ trifluoroacetic acid). The L-dopa content was analyzed using the following gradient: 0-5 minutes, $0-10 \% \mathrm{~B} ; 5-10$ minutes, $10-20 \% \mathrm{~B} ; 10-15$ minutes, $20-30 \% \mathrm{~B} ; 10-17$ minutes, $30-50 \% \mathrm{~B}$; and $17-21$ minutes, $50-0 \% \mathrm{~B}$. The flow rate of the mobile phase was adjusted to $0.3 \mathrm{~mL} /$ minute and the column temperature was set at $40^{\circ} \mathrm{C}$. L-dopa was detected at $280 \mathrm{~nm}$ and identified using commercial standards (Sigma, St. Louis, MO, USA).

The isoflavone extracts from different parts of the faba bean were determined as described by Tepavcevic et al. (2010), with some modifications. Five $\mathrm{mL}$ of $80 \% \mathrm{MeOH}$ and $0.5 \mathrm{~g}$ of each sample were placed in a tube for 4 hours then hydrolyzed with $200 \mu \mathrm{L}$ of $2 \mathrm{~N} \mathrm{NaOH}$. The solutions were neutralized with $50 \mu \mathrm{L}$ of glacial acetic acid. After the sample was centrifuged for 5 minutes at $3000 \mathrm{rpm}$, the collected supernatant was filtered using a $0.45-\mu \mathrm{m}$ syringe filter. The mobile phase contained solvent A (water with $0.05 \%$ formic acid) and solvent $B$ (acetonitrile with $0.05 \%$ formic acid). The isoflavone contents were analyzed using the following gradients: $0-10$ minutes, $15-35 \% \mathrm{~B} ; 10-11$ minutes, $35-15 \% \mathrm{~B}$; and $11-12.5$ minutes, $15 \% \mathrm{~B}$. The flow rate of the mobile phase was adjusted to $0.4 \mathrm{~mL} / \mathrm{min}$, and the column temperature was set at $35^{\circ} \mathrm{C}$. The isoflavones, daidzin, genistin, daidzein, and genistein were detected at $254 \mathrm{~nm}$ and identified using commercial standards (LKT Laboratories Inc., St. Paul, MN, USA).

\section{Statistical analysis}

The chemical analysis data were subjected to the analysis of variance and multiple comparison procedures of the statistical software package SPSS, Version 12 (SPSS Inc., Chicago, IL, USA). The differences were determined as significant at $P \leq 0.05$. When the treatment effect was significant, the means were separated using Duncan's multiple range tests. 


\section{RESULTS}

\section{Morphological characteristics and seed yield traits}

The evaluations of the morphological characteristics are presented in Table 1 and Fig. 1. Ten faba bean genotypes were divided into three botanical varieties on the basis of seed size; PI614810 with small seeds ( $V$. $f a b a$ L. var. minor), seven genotypes (PI252004, PI284345, PI366039, PI369511, PI430715, PI469147 and PI533728) with medium seeds ( $V$. faba L. var. equina) and two genotypes (PI567883 and PI655319) with large seeds ( $V . f a b a$ L. var. major). The faba bean genotypes were divided according to their leaf shape into three types: four genotypes with spatulate, three genotypes with elliptic, and three genotypes with ovate leaves. Significant differences in the leaf and pod size were observed between all the genotypes as well as in most of the seed yields including the number of seeds and the 100-seed weights. The number of seeds from all the genotypes ranged from 65.8 to 160.5 . The PI614810 genotype had the highest number of seeds whereas PI655319 had the lowest. The 100-seed weight was recorded for the PI655319 genotype (135.7 g) as the highest value and for the PI614810 genotype (38.6 g) as the lowest value.

\section{Fatty acids analysis}

The fatty acids identified in the different parts of the faba bean genotypes, along with their retention time (RT) and percentage content, are shown in Table 3 . The leaf extract contained eight fatty acids: myristic acid (C14:0, tetradecanoic acid), palmitic acid (C16:0, hexadecanoic acid), palmitoleic acid (C16:1, 9-hexadecenoic acid), stearic acid (C18:0, octadecanoic acid), oleic acid (C18:1, 9-octadecenoic acid), linolelaidic acid (C18:2, trans-9,12-octadecadienoic acid), phytanic acid (C16:0-( $\left(\mathrm{CH}_{3}\right)_{4}, 3,7,11,15$ tetramethyl hexadecanoic acid), and $\alpha$-linolenic acid (C18:3, $n=3,9,12,15$-octadecatrienoic acid). Palmitic, linolelaidic and $\alpha$-linolenic acids were found to be the major fatty acids present in the faba bean leaf (Supplementary Fig. S1). All of the genotypes had high contents of $\alpha$-linolenic acid, the highest (63.7\%) being found in the leaf of the PI567883 genotype. The leaf of the PI369511 genotype had the highest linolelaidic acid content (13.5\%). The leaf of the PI284345 genotype showed the highest palmitic acid content (15.4\%). The leaf contained eight fatty acids, of which $\alpha$-linolenic acid was the most abundant (58.6-63.7\%).

The extract from the immature pod contained eleven fatty acids: myristic acid, palmitic acid, palmitoleic, stearic acid, oleic acid, linoleic acid, $\gamma$-linolenic acid (C18:3, $n=$ 6, cis-6,9,12-octadecadienoic acid), arachidic acid (C20:0, eicosanoic acid), phytanic acid, $\alpha$-linolenic acid, gondoic acid (C20:1, n = 9, cis-11-eicosenoic acid). Palmitic, linoleic and $\alpha$-linolenic acids were the principal fatty acids presented in the immature pod (Supplementary Fig. S2). All the immature pods of the genotypes had a high content of linoleic acid, with the PI366039 genotype being the highest (58.9\%) and the PI430715 genotype being the lowest (46.9\%). The highest content of palmitic acid in the immature pod was shown to PI614810 genotype (25.8\%), while the lowest content was observed to PI252004 genotype (21.7\%). The PI430715 genotype had the highest content of $\alpha$-linolenic acid in the immature pod $(20.4 \%)$ where other genotypes exhibited PI614810 (18.2\%), PI284345 and PI469147 (12.4\%), PI655319 (11.0\%), PI533728 (10.8\%), PI567883 (10.3\%), PI252004 (9.3\%), PI369511 (8.9\%), and PI366039 (8.4\%).

Ten different fatty acids were identified in the extract of the faba bean seed: palmitic acid, palmitoleic acid, stearic acid, oleic acid, linoleic acid, $\gamma$-linolenic acid, arachidic acid, $\alpha$-linolenic acid, gondoic acid and behenic acid (C22:0, Docosanoic acid). Palmitic, oleic and linoleic acids were presented at high levels in the seed (Supplementary Fig. S3). The highest content of palmitic acid was found in the seed of the PI614810 genotype (20.8\%), whereas the lowest content was in the PI430715 genotype (16.9\%). The linoleic acid contents of seeds of the faba bean genotypes were ranged from $45.7 \%$ in PI430715 to $63.6 \%$ in PI252004. The $\alpha$-linolenic acid contents of the seeds were ranged from $4.9 \%$ to $11.1 \%$ with the PI 430715 genotype having the highest value, approximately $18 \%$ to $66 \%$ higher than that of the other faba bean genotypes.

\section{L-dopa content}

The L-dopa and isoflavone contents of different parts of the faba bean (Table 4$)$ were significantly different $(P \leq$ 


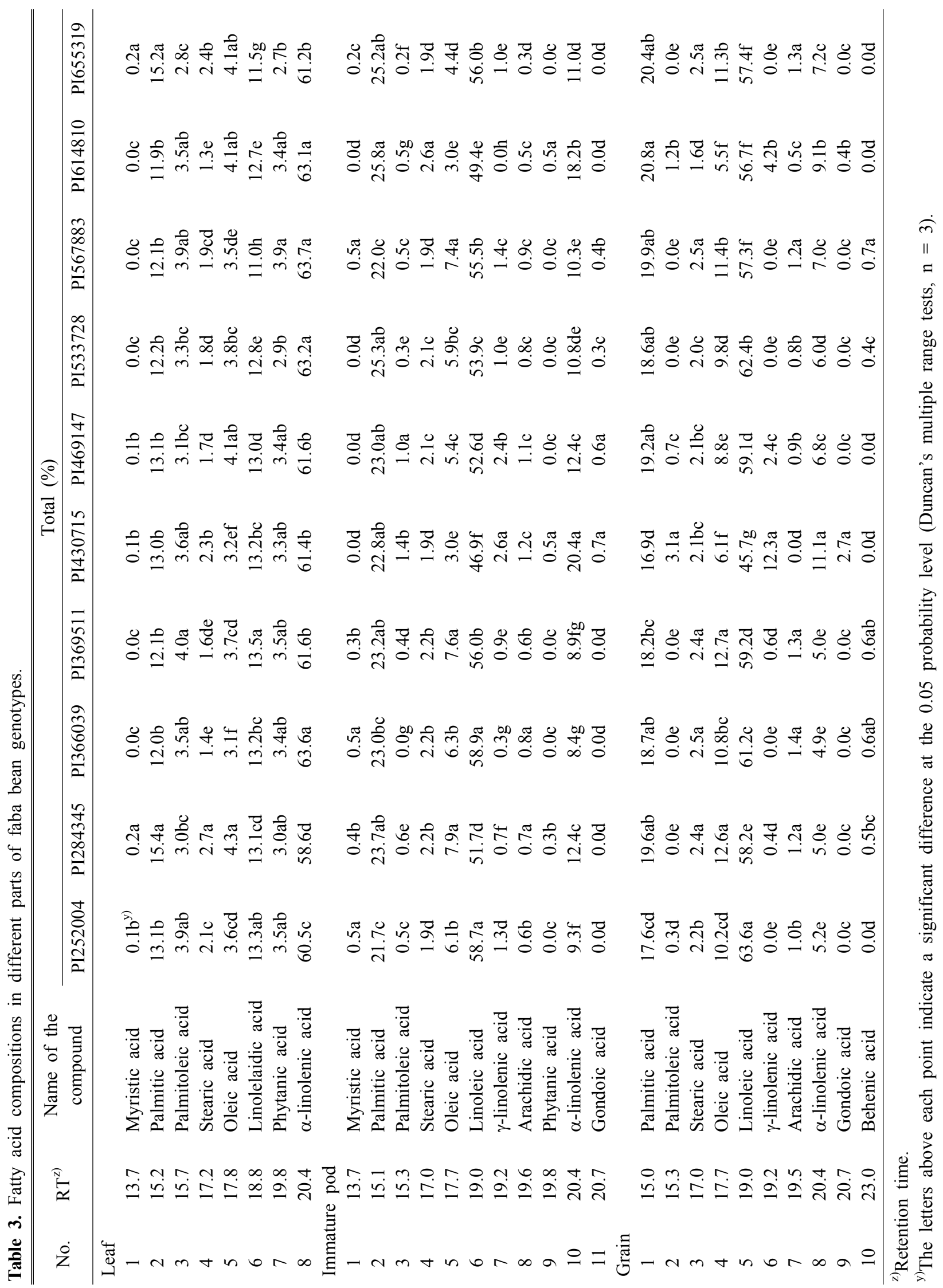


Table 4. L-dopa and isoflavone content in different parts of the faba bean genotypes.

\begin{tabular}{|c|c|c|c|c|c|}
\hline Accession No. & $\begin{array}{l}\text { L-dopa } \\
\text { (mg/g) }\end{array}$ & $\begin{array}{c}\text { Daidzin } \\
(\mathrm{mg} / 100 \mathrm{~g})\end{array}$ & $\begin{array}{c}\text { Genistin } \\
(\mathrm{mg} / 100 \mathrm{~g})\end{array}$ & $\begin{array}{c}\text { Daidzein } \\
(\mathrm{mg} / 100 \mathrm{~g})\end{array}$ & $\begin{array}{c}\text { Genistein } \\
(\mathrm{mg} / 100 \mathrm{~g})\end{array}$ \\
\hline \multicolumn{6}{|l|}{ Leaf } \\
\hline PI252004 & $28.19 \pm 6.09 c^{z)}$ & $10.05 \pm 2.07 \mathrm{a}$ & $2.00 \pm 0.03 c$ & $0.97 \pm 0.27 \mathrm{a}$ & $0.34 \pm 0.02 b$ \\
\hline PI284345 & $39.82 \pm 0.28 \mathrm{a}$ & $0.97 \pm 0.01 \mathrm{c}$ & $0.32 \pm 0.05 f$ & $0.17 \pm 0.02 \mathrm{c}$ & $0.69 \pm 0.21 \mathrm{a}$ \\
\hline PI366039 & $34.61 \pm 3.77 \mathrm{ab}$ & $1.40 \pm 0.53 c$ & $0.38 \pm 0.04 \mathrm{f}$ & $0.09 \pm 0.01 \mathrm{c}$ & $0.66 \pm 0.23 \mathrm{a}$ \\
\hline PI369511 & $34.63 \pm 6.30 \mathrm{ab}$ & $4.33 \pm 1.21 b$ & $4.90 \pm 0.52 b$ & $0.18 \pm 0.02 \mathrm{c}$ & $0.72 \pm 0.06 \mathrm{a}$ \\
\hline PI430715 & $29.02 \pm 5.26 b c$ & $3.71 \pm 1.47 b$ & $2.40 \pm 0.02 \mathrm{c}$ & $0.27 \pm 0.03 c$ & $0.85 \pm 0.44 \mathrm{a}$ \\
\hline PI469147 & $38.63 \pm 6.97 \mathrm{ab}$ & $0.15 \pm 0.00 \mathrm{c}$ & $0.68 \pm 0.12 \mathrm{ef}$ & $0.26 \pm 0.05 \mathrm{c}$ & $-\mathrm{b}$ \\
\hline PI533728 & $32.42 \pm 4.11 \mathrm{ab}$ & $1.83 \pm 0.65 \mathrm{c}$ & $1.33 \pm 0.24 \mathrm{~d}$ & $0.46 \pm 0.08 b$ & $-\mathrm{b}$ \\
\hline PI567883 & $35.26 \pm 4.52 \mathrm{ab}$ & $1.31 \pm 0.53 c$ & $0.56 \pm 0.10 \mathrm{f}$ & $0.10 \pm 0.01 \mathrm{c}$ & $0.65 \pm 0.18 \mathrm{a}$ \\
\hline PI614810 & $33.76 \pm 7.28 \mathrm{ab}$ & $1.84 \pm 0.37 \mathrm{c}$ & $11.46 \pm 0.66 \mathrm{a}$ & $0.39 \pm 0.09 b c$ & $-\mathrm{b}$ \\
\hline PI655319 & $32.79 \pm 4.94 \mathrm{ab}$ & $1.53 \pm 0.44 c$ & $1.13 \pm 0.22 \mathrm{de}$ & $0.23 \pm 0.02 \mathrm{c}$ & $0.07 \pm 0.01 b$ \\
\hline \multicolumn{6}{|l|}{ Immature pod } \\
\hline PI252004 & $19.99 \pm 0.16 f$ & $2.42 \pm 0.75 b c$ & $0.86 \pm 0.05 c$ & $-\mathrm{c}$ & $0.08 \pm 0.00 \mathrm{~cd}$ \\
\hline PI284345 & $23.71 \pm 0.11 \mathrm{e}$ & $2.36 \pm 0.74 b c$ & $1.12 \pm 0.26 \mathrm{c}$ & $0.24 \pm 0.02 \mathrm{a}$ & $0.31 \pm 0.04 \mathrm{a}$ \\
\hline PI366039 & $34.29 \pm 0.07 \mathrm{~d}$ & $3.11 \pm 1.11 \mathrm{~b}$ & $1.11 \pm 0.27 \mathrm{c}$ & $-\mathrm{c}$ & $0.15 \pm 0.01 b$ \\
\hline PI369511 & $20.01 \pm 0.18 \mathrm{f}$ & $2.37 \pm 0.98 b c$ & $1.27 \pm 0.22 \mathrm{c}$ & $0.10 \pm 0.01 b$ & $0.10 \pm 0.00 \mathrm{c}$ \\
\hline PI430715 & $79.58 \pm 0.40 \mathrm{a}$ & $3.16 \pm 0.68 b$ & $3.46 \pm 0.64 \mathrm{a}$ & $0.23 \pm 0.05 \mathrm{a}$ & $0.10 \pm 0.01 \mathrm{c}$ \\
\hline PI469147 & $43.89 \pm 0.50 \mathrm{c}$ & $0.31 \pm 0.05 c$ & $2.37 \pm 0.38 b$ & $0.26 \pm 0.04 \mathrm{a}$ & $0.05 \pm 0.01 \mathrm{~d}$ \\
\hline PI533728 & $20.46 \pm 0.04 f$ & $1.45 \pm 0.42 b c$ & $0.81 \pm 0.15 c$ & $-\mathrm{c}$ & $0.07 \pm 0.00 \mathrm{~d}$ \\
\hline PI567883 & $17.65 \pm 0.06 \mathrm{~g}$ & $1.81 \pm 0.55 b c$ & $1.31 \pm 0.16 \mathrm{c}$ & $-\mathrm{c}$ & $0.07 \pm 0.00 \mathrm{~d}$ \\
\hline PI614810 & $71.37 \pm 0.50 \mathrm{~b}$ & $6.58 \pm 3.15 a$ & $2.72 \pm 0.64 b$ & $-\mathrm{c}$ & $-\mathrm{e}$ \\
\hline PI655319 & $16.31 \pm 0.02 \mathrm{~h}$ & $1.57 \pm 0.49 b c$ & $1.27 \pm 0.14 \mathrm{c}$ & $-\mathrm{c}$ & $0.09 \pm 0.00 \mathrm{~cd}$ \\
\hline \multicolumn{6}{|l|}{ Grain } \\
\hline PI252004 & $0.72 \pm 0.03 \mathrm{~g}$ & $0.60 \pm 0.07 \mathrm{~d}$ & $0.91 \pm 0.10 \mathrm{~d}$ & $-\mathrm{c}$ & $-\mathrm{c}$ \\
\hline PI284345 & $3.97 \pm 0.01 \mathrm{c}$ & $3.13 \pm 0.92 b$ & $1.91 \pm 0.41 \mathrm{c}$ & $0.86 \pm 0.68 b$ & $0.05 \pm 0.01 \mathrm{c}$ \\
\hline PI366039 & $1.76 \pm 0.68 \mathrm{f}$ & $-\mathrm{e}$ & $2.85 \pm 0.33 b c$ & $1.60 \pm 0.50 \mathrm{a}$ & $0.31 \pm 0.04 b$ \\
\hline PI369511 & $3.98 \pm 0.01 \mathrm{c}$ & $3.75 \pm 0.35 b$ & $3.01 \pm 0.22 b$ & $-\mathrm{c}$ & $-\mathrm{c}$ \\
\hline PI430715 & $15.69 \pm 0.10 \mathrm{a}$ & $1.99 \pm 0.07 \mathrm{c}$ & $5.32 \pm 0.91 \mathrm{a}$ & $0.38 \pm 0.03 b$ & $0.94 \pm 0.27 \mathrm{a}$ \\
\hline PI469147 & $5.07 \pm 0.05 c$ & $-\mathrm{e}$ & $4.70 \pm 0.20 \mathrm{a}$ & $0.43 \pm 0.24 b$ & $0.84 \pm 0.28 \mathrm{a}$ \\
\hline PI533728 & $3.36 \pm 0.02 \mathrm{~d}$ & $6.50 \pm 0.19 a$ & $2.97 \pm 0.52 b$ & $0.03 \pm 0.00 \mathrm{c}$ & $-\mathrm{c}$ \\
\hline PI567883 & $2.36 \pm 0.00 \mathrm{e}$ & $3.27 \pm 0.23 b$ & $3.16 \pm 0.40 b$ & $0.05 \pm 0.01 \mathrm{c}$ & $0.03 \pm 0.01 b$ \\
\hline PI614810 & $10.43 \pm 0.03 b$ & $6.79 \pm 0.40 \mathrm{a}$ & $2.76 \pm 0.97 b c$ & $0.06 \pm 0.03 c$ & $0.16 \pm 0.02 b$ \\
\hline PI655319 & $3.52 \pm 0.05 \mathrm{~d}$ & $3.30 \pm 0.02 b$ & $2.38 \pm 0.50 b c$ & $0.23 \pm 0.05 \mathrm{c}$ & $0.16 \pm 0.02 b$ \\
\hline
\end{tabular}

z) The letters above each point indicate a significant difference at the 0.05 probability level (Duncan's multiple range tests, $\mathrm{n}=3)$.

0.05 ) among the faba bean genotypes. Of the different parts, the leaf exhibited the highest L-dopa content of all the different faba bean genotypes except for PI430715 and PI614810 where the highest content was in the immature pod (Supplementary Fig. S4). The L-dopa content in the leaf ranged from $28.19 \mathrm{mg} / \mathrm{g}$ for PI252004 up to 39.82 $\mathrm{mg} / \mathrm{g}$ for PI284345, with a mean value of $33.91 \pm 5.65$ $\mathrm{mg} / \mathrm{g}$. The PI430715 genotype exhibited the highest content of L-dopa in the immature pod $(79.58 \pm 0.40 \mathrm{mg} / \mathrm{g})$ and other genotypes contained relatively low, presenting $71.37 \pm 0.50 \mathrm{mg} / \mathrm{g}$ in PI614810, $43.89 \pm 0.50 \mathrm{mg} / \mathrm{g}$ in PI469147, $34.29 \pm 0.07 \mathrm{mg} / \mathrm{g}$ in PI366039, $23.71 \pm 0.11$ $\mathrm{mg} / \mathrm{g}$ in PI284345, $20.46 \pm 0.04 \mathrm{mg} / \mathrm{g}$ in PI533728, $20.01 \pm$ $0.18 \mathrm{mg} / \mathrm{g}$ in PI369511, $19.99 \pm 0.16 \mathrm{mg} / \mathrm{g}$ in PI252004, $17.65 \pm 0.06 \mathrm{mg} / \mathrm{g}$ in PI567883, and $16.31 \pm 0.02 \mathrm{mg} / \mathrm{g}$ in PI655319, respectively. The L-dopa content in the seed ranged from $0.72 \pm 0.03 \mathrm{mg} / \mathrm{g}$ for PI252004 up to $15.69 \pm$ $0.10 \mathrm{mg} / \mathrm{g}$ for PI 430715 , with a mean value of $5.08 \pm 4.39$ 
Table 5. Correlation coefficients between L-dopa and fatty acid content for faba bean genotypes.

\begin{tabular}{cccccc}
\hline \hline Compounds & Oleic acid & Arachidic acid & Phytanic acid & $\alpha$-linolenic acid & Behenic acid \\
\hline L-dopa & $-0.779 * *$ & $-0.560 * *$ & $0.408^{*}$ & $0.459 *$ & $-0.498^{* *}$ \\
\hline$* P<0.05, * * P<0.01$ & & & & &
\end{tabular}

$\mathrm{mg} / \mathrm{g}$. The L-dopa content of the seed of the PI430715 genotype was approximately 1.4 to 15 times higher than that of the other faba bean genotypes.

The daidzin content in the leaf of the genotypes ranged from $0.15 \pm 0.00$ to $10.05 \pm 2.07 \mathrm{mg} / 100 \mathrm{~g}$. The PI 252004 genotype exhibited the highest content of daidzin, approximately 2.3 to 10 times higher than that of the other faba bean genotypes. The genistin content in the leaf of the genotypes ranged from $0.32 \pm 0.10 \mathrm{mg} / 100 \mathrm{~g}$ for the PI284345 genotype to $11.46 \pm 0.66 \mathrm{mg} / 100 \mathrm{~g}$ for the PI614810 genotype. The genistin content in the leaf of the PI614810 genotype was approximately 2.3 to 10 times higher than in that of the other faba bean genotypes. The daidzein contents in the leaf of the genotypes ranged from 0.09 to $0.97 \mathrm{mg} / 100 \mathrm{~g}$ with the highest content in the PI252004 genotype. The genistein contents in the leaf of seven genotypes ranged from 0.07 to $0.72 \mathrm{mg} / 100 \mathrm{~g}$ whereas no genistein detected in the PI469147, PI533728 and PI614810 genotypes. The highest level of daidzin content in the immature pod was found in the for PI614810 genotype $(6.58 \pm 3.15 \mathrm{mg} / 100 \mathrm{~g})$, and the lowest value was shown in that of the PI469147 genotype $(0.31 \pm 0.05$ $\mathrm{mg} / 100 \mathrm{~g})$. The genistin content in the immature pods of all genotypes was ranged from $0.81 \mathrm{mg} / 100 \mathrm{~g}$ for PI533728 up to $3.46 \pm 0.64 \mathrm{mg} / 100 \mathrm{~g}$ for PI430715. The daidzein contents in the immature pod of all genotypes were less than $0.26 \mathrm{mg} / 100 \mathrm{~g}$. The highest genistein content in the immature pod was observed in the PI284345 genotype. The daidzin contents in the seed of eight genotypes were ranged from 0.60 up to $6.79 \mathrm{mg} / 100 \mathrm{~g}$. The higher contents of daidzin were shown in the PI533728 and PI614810 genotypes while no daidzin was detected in the PI366039 and PI469147 genotypes. The genistin contents in the seed of the genotypes were ranged from 0.91 to $5.32 \mathrm{mg} / 100 \mathrm{~g}$ with the highest content in PI430715 genotype. The daidzein in the seeds of the genotypes was not detected in PI252004 and PI369511, but it was contained up to 1.60 $\mathrm{mg} / 100 \mathrm{~g}$ in the PI366039 genotype. The genistein contents in the seeds of all the genotypes were less than $0.94 \mathrm{mg} / 100 \mathrm{~g}$ (Supplementary Fig. S5).

\section{Correlation analysis}

The values of Pearson's correlation coefficient are shown in Table 5. The L-dopa content was positively correlated $(P \leq 0.05)$ with the contents of phytanic acid and $\alpha$-linolenic acid. The L-dopa content was negatively correlated $(P \leq 0.01)$ with the contents of oleic acid, arachidic acid, and behenic acid. The morphological characteristics were not significantly correlated with the contents of fatty acids, L-dopa, and isoflavones. The L-dopa content was significantly correlated $(P \leq 0.05)$ with the fatty acid contents.

\section{DISCUSSION}

Faba bean (Vicia faba L.) is one of the most important legumes for its functional compounds. This is the first report on the L-dopa, isoflavone, and fatty acid value of the different parts of the selected faba bean in Korea environment. Faba bean is widely used in cereal-dominated rotations as break crop, partly because of its high input of nitrogen in the soil. Korean imports for large amount of legumes every year. Faba bean is most advantageous as a legume crop that can be cultivated in the winter or spring season. The results of this study revealed the presence of functional compounds in the different part of selected faba bean with high yield by spring sowing. It is routinely used to access faba bean cultivates and breeding programs. Unfortunately, Kim (2006) reported that faba bean in fall season seeding showed higher yield with large grain size expressing earlier maturing than those of spring seeding in southern Korea. Thus, study on the winter cultivation is necessarily. The most important characteristics for im- 
proving the seed yield of faba bean were reported to be 100-seed weight, number of seeds per plant and seed size (Agung and McDonald 1998). Normally, the large and medium seeds genotypes offered more seed yield than small seeds (Agung and McDonald 1998; Kim 2006).

This study revealed the presence of fatty acid in the different parts of the faba bean by GC-MS. The leaf contained 8 fatty acid, of which $\alpha$-linolenic acid was the most fatty acid (58.6-63.7\%). Similarly, Arbaoui and Link (2008), reported that the main fatty acid (51-57\%) in the leaf and stem of faba bean was $\alpha$-linolenic acid. The present study has detected 11 fatty acids in the immature pod, of which linoleic acid was the most abundant. There have been no studies on the fatty acid composition of the immature pod of faba bean. The levels of linoleic acid in the immature pod of the faba bean genotypes were higher than those reported for Japanese soybean cultivars, except for the PI430715 and PI614810 genotypes which had similar linoleic acid contents (Kumar et al. 2007). The linoleic acid content was lower in the immature pods of the PI430715 and PI614810 genotypes than in those of the other genotypes. In contrast, the $\alpha$-linolenic acid content of the immature pod of the PI430715 and PI614810 genotypes was approximately twice that in pods of the other genotypes. The seeds contained ten fatty acids, of which linoleic acid was the most abundant (45.7-63.6\%), findings similar to those of Yoshida et al. (2009) (43.6-69.8\% for triacylglycerols obtained from four faba bean cultivars). The $\alpha$-linolenic acid contents of the seeds of the PI430715 and PI614810 genotypes were higher than those of the other genotypes. $\alpha$-linolenic acid, a polyunsaturated fatty acid abundant in plant vegetable oils, has medicinal properties so is used to treat heart disease, high cholesterol level, and high blood pressure (Furuhashi and Hotamisligil 2008). Our results suggest that PI430715 and PI614810 are potentially the most appropriate faba bean genotypes for improving health benefits through their high contents of functional compounds.

Nowadays, it has been trying that use of genetically modified plants to produce L-dopa for the treatment of Parkinson's disease has been proposed as an alternative to produce it synthetically (Longo et al. 1974; Rabey et al. 1993; Burbano et al. 1995; Ando et al. 1999; Randhir and
Shetty 2004; Goyoaga et al. 2008; Fox and Brotchie 2014). We observed significant differences in L-dopa content between the different parts of the faba bean genotypes. The leaf and immature pod showed higher levels of L-dopa than the seed so that the tissues could be a good source for producing the compound promising for treating Parkinson's disease. Previous studies have revealed that L-dopa presents in several tissues of the faba bean plant: the sprout $2-3 \%$, leaf $6 \%$, immature pod $6 \%$, flower $7 \%$, immature seed 4\%, and mature seed less than 1\% (Burbano et al. 1995; Goyoaga et al. 2008; Hu et al. 2015). Burbano et al. (1995) reported that the L-dopa content decreased significantly as the seed was developed. The L-dopa levels of the leaf observed in the present study were similar to those reported by $\mathrm{Hu}$ et al. (2015) for six faba bean cultivars (18.2-48.7 mg/g dry weight). The L-dopa concentrations in the seed and immature pod for the PI430715 and PI614810 genotypes were higher than in those of the other genotypes and also higher than those reported by Kirakosyan et al. (2004) in the seed. The L-dopa concentrations observed in the immature pod were similar to those reported by Goyoaga et al. (2008) for the embryo axes of two faba bean cultivars harvested up to 9 days after imbibition. This also suggests that the PI430715 and PI614810 genotypes are potentially the most appropriate materials for helping treat Parkinson's disease (Goyoaga et al. 2008; Hu et al. 2015).

In this study, we analyzed the isoflavone content in the different parts of faba bean genotypes. We observed significant differences $(P<0.05)$ for most of the isoflavone content including daidzin, genistin, daidzein and genistein. The levels of daidzin and genistin were generally higher than those of daidzein and genistein in each part. The data also indicate that is wide variation among genotypes and parts in the levels of isoflavones analyses. These findings are similar to those described by Kirakosyan et al. (2004). Faba bean that have traditionally been utilized in animal feed are known to be relatively rich in isoflavones (Kirakosyan et al. 2004; Crepon 2010). We therefore analyses the distribution of isoflavones in different parts of faba bean. These results are important particularly for industries that produce products since it can grind and processing to avoid excessive losses of isoflavones. 
The L-dopa content was significant correlated $(P<$ $0.05)$ with fatty acids. Previous studies have revealed that unsaturated fatty acids, such as oleic, linoleic, and $\alpha$-linolenic acids, can decrease the tyrosinase levels, while saturated fatty acids, such as palmitic and stearic acids, can increase them (Ando et al. 1999). L-dopa can also be synthesized by the hydroxylation of tyrosinase (L-tyrosine) though a series of enzymatic and chemical steps (Shetty et al. 2002). Julien et al. (2006) have reported that administering L-dopa to Parkinsonian monkey's brain decreased their level of unsaturated fatty acids.

\section{ACKNOWLEDGEMENTS}

This work was supported by Radiation Technology R\&D program (NRF-2017M2A2A6A05018538) through the National Research Foundation of Korea funded by the Ministry of Science and ICT.

\section{REFERENCES}

Adsule RN, Akpapunam M. Faba bean (Vicia faba L.). 1996. In: E. Nwokolo, J. Smartt (eds.). Food and feed from legumes and oilseeds. Springer, Boston, MA, U.S.A.

Agung S, McDonald GK. 1998. Effects of seed size and maturity on the growth and yield of faba bean (Vicia faba L.). Aust. J. Agr. Res. 49: 79-88.

Ando H, Funasaka Y, Oka M, Ohashi A, Furumura M, Matsunaga J, et al. 1999. Possible involvement of proteolytic degradation of tyrosinase in the regulatory effect of fatty acids on melanogenesis J. Lipid Res. 40: 1312-1316.

Arbaoui M, Link W. 2008. Effect of hardening on frost tolerance and fatty acid composition of leaves and stems of a set of faba bean (Vicia faba L.) genotypes. Euphytica 162: 211-219.

Burbano C, Cuadrado C, Muzquiz M, Cubero JI. 1995. Variation of favism-inducing factors (vicine, convicine and L-DOPA) during pod development in Vicia faba $\mathrm{L}$ Plant. Foods. Hum. Nutr. 47: 265-274.

Crepon K, Marget P, Peyronnt C, Carrouee B, Arese P, Duc G. 2010. Nutritional value of faba bean (Vicia faba L.) seeds for feed and food. Field Crops Res. 115: 329-339.

Fox SH, Brotchie JM. 2014. Levodopa-induced dyskinesia in Parkinson's disease. Springer, London, England.

Furuhashi M, Hotamisligil GS. 2008. Fatty acid-binding proteins: role in metabolic diseases and potential as drug targets. Nat. Rev. Drug Discov. 7: 489-503.

Goyoaga C, Burbano C, Cuadrado C, Varela A, Guillamón E, Pedrosa MM, et al. 2008. Content and distribution of vicine, convicine and L-DOPA during germination and seedling growth of two Vicia faba L. varieties. Eur. Food Res. Technol. 227: 1537-1542.

Hamberg M, Fahistadius P. 1992. On the specificity of a fatty acid epoxygenase in broad bean (Vicia faba L.) Plant Physiol. 99: 987-995.

Hu J, Kwon SJ, Park JJ, Landry E, Mattinson DS, Gang DR. 2015. LC-MS determination of L-DOPA concentration in the leaf and flower tissues of six faba bean (Vicia faba L.) lines with common and rare flower colors. Functional Foods in Health and Disease 5: 243-250.

Julien C, Berthiaume L, Hadj-Tahar A, Rajput AH, Bedard PJ, Paolo TD, et al. 2006. Postmortem brain fatty acid profile of levodopa-treated Parkinson disease patients and parkinsonian monkeys. Neurochem. Int. 48: 404-414.

Kim SK. 2006. Studies on establishment of cultural practices and utilization of faba bean (Vicia faba L.) PhD thesis, Gyeongsang National University, Korea.

Kirakosyan A, Kaufman PB, Duke JA, Warber S, Steven B. 2004. The Production of L-dopa and isoflavones in seed and seedlings of different cultivars of Vicia faba L. (fava bean). Evidence-Based Integ. Med. 1: 131-135.

Kumar V, Rani A, Billore SD, Chauhan GS. 2007. Physicochemical properties of immature pods of Japanese soybean cultivars. Int. J. Food Prop. 9: 51-59.

Longo R, Castellani A, Sberze P, Tibolla M. 1974. Distribution of L-DOPA and related amino acid in Vicia. Phytochem. 13: 167-171.

Rabey JM, Vered Y, Shahtai H, Graff E, Harsat A, Korezyn AD. 1993. Broad bean (Vicia faba) consumption and Parkinson's disease. Adv. Neurol. 60: 681-684.

Randhir R, Shetty K. 2004. Microwave-induced stimulation of L-DOPA, phenolics and antioxidant activity in fava bean (Vicia faba) for Parkinson's diet. Process Biochem. 39: 1775-1784.

Robert WW, Griffiths DW. 1984. Variation in the oil content and fatty acid composition of field beans (Vicia faba) and 
peas (Pisum spp.). J. Sci. Food. Agric. 35: 1282-1289.

Ryu J, Kwon SJ, Jo YD, Choi HL, Kang KY, Nam BM, et al. 2017. Fruit quality and chemical contents of hybrid boysenberry (Rubus ursinus) lines developed by hybridization and gamma irradiation. Plant Breed. Biotech. 5: 228-236.

Shetty P, Atallah MT, Shetty K. 2002. Effects of UV treatment on the proline-linked pentose phosphate pathway for phenolics and L-DOPA synthesis in dark germinated Vicia faba. Process Biochem. 37: 1285-1295. Takashi H, Takahashi I, SaijoMasaaki K, Tomohide F, Tomoko N, Yuji M. 2011. Quantitative Determination of
L-DOPA in Dietary Supplements Containing Mucuna pruriens by High Performance Liquid Chromatography. Chiba Prefecture Wei Yan Ann. Rep. 60: 53-56.

Tepavcevic V, Atanackovic M, Miladinovic J, Malencic D, Popovic J, Cvejic J. 2010. Isoflavone composition, total polyphenolic content, and antioxidant activity in soybeans of different origin. J. Med. Food 13: 657-664.

Yoshida, H, Saiki M, Yoshida N, Tomiyama Y, Mizushina Y. 2009. Fatty acid distribution in triacylglycerols and phospholipids of broad beans (Vicia faba) Food Chem. 112: 924-928. 